\title{
Shared Decision-Making and Patient Satisfaction in Japanese Rheumatoid Arthritis Patients: A New "Preference Fit" Framework for Treatment Assessment
}

Jörg Mahlich (D) · Ulrike Schaede · Rosarin Sruamsiri

Received: March 25, 2019 / Published online: May 2, 2019

(c) The Author(s) 2019

\section{ABSTRACT}

Introduction: We have developed a new framework to assess shared decision-making (SDM) as a tool to improve patient satisfaction. This framework is based on a "preference fit" index that relates SDM to patient treatment preferences and patient satisfaction in a sample of rheumatoid arthritis (RA) patients in Japan.

Methods: We surveyed 500 RA patients in Japan and explored the interactions between the treatment preference fit index, SDM, and overall patient satisfaction.

Results: Our new preference fit index reveals significant impact on patient satisfaction: the

Enhanced Digital Features To view enhanced digital features for this article go to: https://doi.org/10.6084/ m9.figshare.8006240.

J. Mahlich

Health Economics and Outcomes Research, Janssen-

Cilag, Neuss, Germany

J. Mahlich ( $\square)$

Düsseldorf Institute for Competition Economics

(DICE), University of Düsseldorf, Düsseldorf,

Germany

e-mail: joerg.mahlich@gmail.com

U. Schaede

University of California, San Diego, CA, USA

R. Sruamsiri

Center of Pharmaceutical Outcomes Research,

Naresuan University, Phitsanulok, Thailand better the fit between SDM and patient preferences, the higher the patient satisfaction with the current treatment. Patients treated with biologic agents were more satisfied. Patients suffering from depression or migraines scored significantly lower both on our preference fit measure and for overall patient satisfaction.

Conclusion: The association between depression and a low treatment preference fit suggests that depression may pose challenges to SDM and that doctors in Japan are less attuned to the SDM preferences of depressed patients.

Funding: Janssen Pharmaceutical KK.

Keywords: Depression; Japan; Patient satisfaction; Rheumatoid arthritis; Shared decision-making; Treatment preference fit

\section{INTRODUCTION}

Since the 1990s, shared decision-making (SDM) as a component of personalized patient care has attracted a great deal of interest, in particular in North America and Europe. The introduction of informed consent rules, new demands regarding consumer advocacy and informed choice, "doctor hopping," and advances in treatment options have together led to the transition of SDM from the acute care setting only to the chronic care setting as well [1]. Moreover, there is a treatment paradigm change, one that moves away from the more traditional "paternalistic" 
approach and toward joint doctor-patient discussions of treatment options [2]. It has been shown that both patient satisfaction and treatment outcomes are associated with trust, cultural competence, and SDM [3-8]. However, despite the efforts of doctors to incorporate SDM into their treatment approach, research has revealed a discrepancy between doctors' perception of patients' SDM needs and patients' preferences [9].

Current knowledge on SDM is constrained by two factors. First, existing research is focused on Western countries, and cultural nuances remain unexplored, especially for Asia, even though SDM preferences are changing in the latter regions as well [10-13]. Second, most SDM studies have involved cancer patients for whom treatment decisions often necessitate significant lifestyle choices. Research on SDM has been more ambiguous in patients with chronic disease. Whereas SDM has been shown to improve adherence by patients with diabetes or hypertension [e.g., 14-16], SDM is still rarely applied to mental health patients consulting a specialist for the first time [17-19].

Here, we present the results of a survey study of rheumatoid arthritis (RA) patients in Japan in which we explore the interaction between SDM, patient satisfaction, and depression. The goal of this study was to relate three aspects of patient care that have hitherto been viewed separately: (1) benefits of SDM, as perceived by patients; (2) patient treatment satisfaction; and (3) the influence of patient comorbidities on both of the former two aspects. We have developed a new matrix of a "treatment preference fit" as well as a scoring system to assess the match between the physician's SDM efforts and patient preferences. This score is then combined with psychiatric conditions and other afflictions outside the treating doctor's specialty to explore how overall patient satisfaction is affected.

Studies have shown that chronic disease is associated with a higher incidence of psychiatric disorders and that $20-40 \%$ of RA patients suffer from some degree of depression, perhaps due to the debilitating effects of the disease or because RA and depression may be caused by similar inflammations [20-24]. A Canadian study found that $10 \%$ of RA patients suffer from clinically relevant levels of major depression [25]. Depression, in turn, may affect the patient's interest in SDM and compliance with the treatment regimen, and thereby drive overall treatment satisfaction.

Japan offers an interesting case study for this type of research. Given Japan's rapidly ageing society, RA is a frequent affliction. Traditionally, Japanese doctors have been described as being on the "paternalistic," or prescriptive, end of the doctor-patient relationship spectrum, and older patients in particular are said to revere physicians as authority figures [26]. However, this has begun to change in recent years, and SDM has been introduced into Japanese Medical School curricula as well as into treatment practice [27-31]. We were therefore interested to determine the extent to which Japanese patients express an interest in being involved in treatment decisions.

It has also been shown that depression remains comparatively underdiagnosed and undertreated in Japan compared to the USA $[32,33]$. For example, it has been estimated that the number of prescriptions of antidepressants in the USA per capita exceeds that of Japan by a factor of five [32]. Cultural reasons are sometimes invoked for the lack of diagnosis of depression in general, including a fear of social stigma and a perceived need to show strength of character [34]. However, it has also been suggested that rheumatologists occasionally neglect to consider depression as a possible additional affliction [35]. For our study, this translates into a larger portion of survey respondents without treatment, which allows for a granular picture of the effects of depression on patient satisfaction.

The purpose of this study was to draw attention not to the processes of SDM, but to the patient satisfaction which derives from SDM [36]. SDM provides a mechanism toward the end goal of increasing adherence to the chosen treatment regimen. Thus, rather than focusing on SDM per se, physicians may want to pay attention to the "preference fit," i.e., the importance of fit between what the patients want and what they get. 


\section{METHODS}

In this study, we used cross-sectional data to link our treatment preference fit index with patient satisfaction, following which we explored differences between RA patients with depression and those without depression. To this end, a cross-sectional online survey was conducted in Japan, from July to August 2016, which drew from a patient pool of 1000 patients who fulfilled the inclusion criteria of (1) having been diagnosed with RA for $>1$ year and (2) having been treated with at least one RA-related medication. A total of 500 RA patients responded to the questionnaire, with the age and gender distribution of the respondents similar to those of the national pool of RA patients in Japan. The survey was administered by Medilead Inc., a Tokyo-based marketing research agency specializing in the healthcare industry. Individual identifying information was not obtained.

\section{Questionnaire}

The survey contained questions on both personal characteristics (age, gender, marital status, education, geography, work, income) and clinical characteristics (time since diagnosis, severity of disease, comorbidity, depression, current medical treatment). Severity of disease was assessed using the validated Japanese version of the Stanford Health Assessment Questionnaire (HAQ) [37]. This questionnaire contains eight categories: dressing and grooming, arising, eating, walking, hygiene, reach, grip, and activities.

The survey also contained questions regarding mood, using the Japanese language version of the Patient Health Questionnaire-9 item (PHQ-9), which has been validated as a depression screening tool in Japanese hospitals [38]. The PHQ-9 scores have three categories: minimal (0-4), mild (5-9), and moderate to severe $(\geq 10)$.

To assess patient preferences for SDM, we adapted the questionnaire developed by Baars et al. [39] for patients with chronic disease in the Netherlands. In this context, this questionnaire contained two questions. First, "How important is it that the physician involves you in the decisions concerning your medical treatment?" The possible answers to this question range, on a 4-point Likert scale, from (a) very important, (b) quite important, (c) quite unimportant, and (d) totally unimportant. To balance the panel for the regression analysis, we collapsed the last two answers into one, (c) "not much," to create a 3-step variable of "high," "somewhat," and "not much." The second question was: "To what degree does your doctor take your opinions and recommendations into consideration when making treatment decisions?" The possible answers are: (a) very much, (b) somewhat, (c) not much, and (d) not at all. Again, for the regression analysis, we collapsed the last two answers into one, (c) "not much," to create a 3-step variable of "high," "somewhat," or "not much."

Finally, we also asked, in overall terms: "How satisfied are you with your treatment?", with answers ranging from (a) very satisfied, (b) satisfied, (c) not satisfied, to (d) very dissatisfied. For purposes of panel balance in the regression analysis, we collapsed the last two answers into one, (c) "dissatisfied," to create a 3-step variable of "very satisfied," "satisfied," or "dissatisfied."

\section{Treatment Preference Fit Index}

We developed a matching grid to assess the fit between what patients want and what they get; i.e., we matched patient SDM preferences with their perception of physician responsiveness. Table 1 outlines our scoring system for the treatment preference fit index to establish a metric to assess fit in treatment decision-making inclusion.

In this table, a "good fit" situation, scored with 3 points, is one in which either the patient considers SDM to be very important and the physician involves the patient very actively in the treatment decision, or the patient has no interest at all in SDM, and the physician in fact makes unilateral decisions. A "poor fit" (2 points) is a situation in which a patient's preference is one level different from the perceived SDM involvement. Finally, a "bad fit" (1 point) 
Table 1 Methodology to create the treatment "preference fit" index

\begin{tabular}{llll}
\hline Preference & \multicolumn{2}{l}{ Current involvement } \\
\cline { 2 - 4 } & High & Somewhat & Not so much \\
\hline Important & Good fit & Poor fit & Bad fit \\
Somewhat & Poor fit & Good fit & Poor fit \\
Unimportant & Bad fit & Poor fit & Good fit \\
\hline
\end{tabular}

The questions asked to construct this index were based on Baars et al. [39] study. Question (1): "How important is it that the physician involves you in the decisions concerning your medical treatment?"; possible answers range, on a 4-point Likert scale, from (a) very important, (b) quite important, (c) quite unimportant, to (d) totally unimportant. The answers were then collapsed into three categories by combining the last two into "unimportant". Question (2): "To what degree does your doctor take your opinions and recommendations into consideration when making treatment decisions?"; possible answers range from (a) highly, (b) somewhat; (c) not much, to (d) not at all. The answers were then collapsed into three categories by combining the last two into "not much"

is a situation in which patient preferences are opposite to their perception of the treatment offered.

In this paper we explored the potential of this new "preference fit" index. We are aware that this instrument has not been validated yet, in particular with regard to a possible bias by patients who are uninterested in SDM and perceive more SDM involvement than they objectively receive. We based our index on survey questions used in previous research and have left the validation of these studies to future studies.

\section{Statistical Analysis}

Sample summary statistics (Table 2) included a difference in tests of significance, based on the chi-square test, to determine whether there was a significant difference between the expected frequencies and the observed frequencies in one or more categories. To explore factors associated with treatment satisfaction, we performed ordered logistic regression analysis using Stata software (StataCorp, College Station, TX, USA).
A $P$ of $<0.05$ (two-sided) was considered to indicate statistical significance. Model fit was assessed using pseudo- $R^{2}$.

\section{Ethics}

This study was performed in accordance with the guidelines of all involved institutions and approved by the Janssen approval committee (ID 50487). It was also performed in accordance with the Helsinki Declaration of 1964 and its later amendments. Informed consent was obtained from all patients in order to collect their personal information, with the exception of individual-specific information capable of identifying individuals, which was not collected. The authors were not involved in the collection of this data. Data were collected by the database provider, and patients were informed that their data would be used for research.

\section{RESULTS}

\section{Patient Characteristics}

Patient summary statistics, grouped by level of satisfaction with the current treatment, are presented in Table 2. On average, the RA patients who responded were 54 years old. Of the total sample, $67 \%$ were female, $36 \%$ had only a high school degree or less, and $40 \%$ had a college degree. Half of the respondents were employed (40\% held long-term [full-time] positions). Individual income levels tended toward the lower end of the spectrum: whereas $27 \%$ of the total RA patients had an individual income of less than Yen 800,000 per year (roughly US $\$ 8000$ at the time; a reflection of the fact that many were not in the workforce), at the household level (not reported in Table 2), $20 \%$ of patients reported a total income of less than Yen 3.1 million (roughly US \$30,000), half of the patients reported a total income of between Yen 3.1 million and Yen 9.7 (US $\$ 30,000-\$ 100,000)$, and 10\% had a household income exceeding Yen 9.7 million. 
Table 2 Patient characteristics-personal information

\begin{tabular}{|c|c|c|c|c|c|}
\hline $\begin{array}{l}\text { Patient personal } \\
\text { characteristics }\end{array}$ & $\begin{array}{l}\text { Overall } \\
\text { patient } \\
\text { sample }\end{array}$ & $\begin{array}{l}\text { Very satisfied with } \\
\text { current treatment }\end{array}$ & $\begin{array}{l}\text { Satisfied with } \\
\text { current treatment }\end{array}$ & $\begin{array}{l}\text { Dissatisfiedwith } \\
\text { current treatment }\end{array}$ & $P$ value \\
\hline Patients $(n)$ & $500(100)$ & $189(38)$ & $257(51)$ & $54(11)$ & \\
\hline Age (years) & $54.28 \pm 10.02$ & $54.58 \pm 10.34$ & $54.35 \pm 9.87$ & $52.87 \pm 9.62$ & 0.715 \\
\hline$\leq 50$ & $178(36)$ & $68(36)$ & $85(33)$ & $25(46)$ & \\
\hline $51-60$ & $196(39)$ & $70(37)$ & $107(42)$ & $19(35)$ & \\
\hline$>60$ & $126(25)$ & $51(27)$ & $65(25)$ & $10(19)$ & \\
\hline Gender & & & & & 0.876 \\
\hline Male & $163(33)$ & $59(31)$ & $86(33)$ & $18(33)$ & \\
\hline Female & $337(67)$ & $130(69)$ & $171(67)$ & $36(67)$ & \\
\hline Marital status & & & & & 0.075 \\
\hline Single & $97(19)$ & $32(17)$ & $59(23)$ & $6(11)$ & \\
\hline Married & $403(81)$ & $157(83)$ & $198(77)$ & $48(89)$ & \\
\hline Highest education & & & & & 0.179 \\
\hline High school or less & $180(36)$ & $56(30)$ & $104(40)$ & $20(37)$ & \\
\hline College & $120(24)$ & $49(26)$ & $56(22)$ & $15(28)$ & \\
\hline $\begin{array}{l}\text { Bachelor degree or } \\
\text { higher }\end{array}$ & $200(40)$ & $84(44)$ & $97(38)$ & $19(35)$ & \\
\hline Occupation & & & & & 0.895 \\
\hline $\begin{array}{l}\text { Full-time } \\
\text { employment }\end{array}$ & $200(40)$ & $73(39)$ & $103(40)$ & $24(44)$ & \\
\hline $\begin{array}{l}\text { Nonregular } \\
\text { employment }\end{array}$ & $77(15)$ & $26(14)$ & $42(16)$ & $9(17)$ & \\
\hline Housewife & $141(28)$ & $58(31)$ & $68(26)$ & $15(28)$ & \\
\hline Retired & $20(4)$ & $10(5)$ & $9(4)$ & $1(2)$ & \\
\hline Unemployed & $56(11)$ & $19(11)$ & $32(12)$ & $5(9)$ & \\
\hline Other & $6(1)$ & $3(1)$ & $3(1)$ & $0(0)$ & \\
\hline Region & & & & & 0.102 \\
\hline Hokkaido & $26(5)$ & $5(3)$ & $14(5)$ & $7(13)$ & \\
\hline Tohoku & $23(5)$ & $8(4)$ & $15(6)$ & $0(0)$ & \\
\hline Kanto & $230(46)$ & $90(48)$ & $114(44)$ & $26(48)$ & \\
\hline Chubu & $63(13)$ & $27(14)$ & $30(12)$ & $6(11)$ & \\
\hline Kansai & $95(19)$ & $32(17)$ & $52(20)$ & $11(20)$ & \\
\hline Chugoku & $21(4)$ & $9(5)$ & $12(5)$ & $0(0)$ & \\
\hline
\end{tabular}


Table 2 continued

\begin{tabular}{|c|c|c|c|c|c|}
\hline $\begin{array}{l}\text { Patient personal } \\
\text { characteristics }\end{array}$ & $\begin{array}{l}\text { Overall } \\
\text { patient } \\
\text { sample }\end{array}$ & $\begin{array}{l}\text { Very satisfied with } \\
\text { current treatment }\end{array}$ & $\begin{array}{l}\text { Satisfied with } \\
\text { current treatment }\end{array}$ & $\begin{array}{l}\text { Dissatisfiedwith } \\
\text { current treatment }\end{array}$ & $P$ value \\
\hline Shikoku & $11(2)$ & $2(1)$ & $8(3)$ & $1(2)$ & \\
\hline Kyushu & $31(6)$ & $16(8)$ & $12(5)$ & $3(6)$ & \\
\hline $\begin{array}{l}\text { Annual income } \\
\text { (Yen) }\end{array}$ & & & & & 0.989 \\
\hline$<800,000$ & $135(27)$ & $51(27)$ & $69(27)$ & $15(28)$ & \\
\hline $0.8-1.6$ million & $89(18)$ & $38(20)$ & $40(16)$ & $11(20)$ & \\
\hline 1.6-3.1 million & $83(17)$ & $27(14)$ & $47(18)$ & $9(17)$ & \\
\hline $3.1-3.7$ million & $24(5)$ & $9(5)$ & $14(5)$ & $1(2)$ & \\
\hline 3.7-5.7 million & $41(8)$ & $17(9)$ & $20(8)$ & $4(7)$ & \\
\hline $5.7-7.7$ million & $32(6)$ & $11(6)$ & $17(7)$ & $4(7)$ & \\
\hline 7.7-9.7 million & $15(3)$ & $4(2)$ & $9(4)$ & $2(4)$ & \\
\hline $9.7-11.6$ million & $9(2)$ & $5(3)$ & $3(1)$ & $1(2)$ & \\
\hline 11.6-15.1 million & $7(1)$ & $4(2)$ & $3(1)$ & $0(0)$ & \\
\hline$>15.1$ million & $2(0)$ & $1(1)$ & $1(0)$ & $0(0)$ & \\
\hline Unknown & $63(13)$ & $22(11)$ & $34(13)$ & $7(13)$ & \\
\hline
\end{tabular}

Values in table are presented as the mean \pm standard deviation (SD) or as the number if respondents with the percentage of total in each column in parenthesis

$P$ values are based on the chi-square test

The sample was geographically balanced, with $46 \%$ of respondents from Kanto (Tokyo metropolitan region) and 19\% from Kansai (Osaka metropolitan region).

Analysis of the clinical parameters (Table 3) revealed that time since diagnosis was about 11 years at the time of the survey and that the average HAQ score was 0.4 , indicating a mild form of RA. Younger patients and patients with higher HAQ scores were less satisfied with their treatment than those who were older and had lower HAQ scores, although this difference was not significant. Hypertension and high cholesterol were the most common comorbidities. Two-thirds of patients were treated with a conventional disease-modifying antirheumatic drug, while $34 \%$ received a biologic agent, such as tumor necrosis factor alpha (TNF- $\alpha$ ) or interleukin-6 (IL-6).
Responses to the PHQ-9 questionnaire indicated that $24 \%$ of respondents were mildly depressed and that $11 \%$ were severely depressed. In contrast to some studies conducted in Germany [40], depression was not associated with a lower demand for being involved in the decision-making process. However, depression was associated with treatment dissatisfaction: whereas only $7.7 \%(25 / 324)$ of patients without depression were dissatisfied with their current treatment, $27.6 \%(16 / 58)$ of patients with moderate or severe depression were dissatisfied. While the overall SDM treatment preference fit was very high, with only $4 \%$ reporting a bad or poor fit, a poor fit was associated with reduced patient satisfaction: for $19 \%$ of dissatisfied patients, the treatment preference fit was either poor or bad. 
Table 3 Patient characteristics-clinical parameters

\begin{tabular}{|c|c|c|c|c|c|}
\hline $\begin{array}{l}\text { Patient clinical } \\
\text { characteristics }\end{array}$ & $\begin{array}{l}\text { Overall } \\
\text { patient } \\
\text { sample }\end{array}$ & $\begin{array}{l}\text { Very satisfied } \\
\text { with current } \\
\text { treatment }\end{array}$ & $\begin{array}{l}\text { Satisfied } \\
\text { with current } \\
\text { treatment }\end{array}$ & $\begin{array}{l}\text { Dissatisfied } \\
\text { with current } \\
\text { treatment }\end{array}$ & $P$ value \\
\hline Years since diagnosis (years) & $10.67 \pm 8.63$ & $11.21 \pm 8.46$ & $10.68 \pm 8.91$ & $8.80 \pm 7.72$ & 0.391 \\
\hline$\leq 5$ & $165(33)$ & $53(28)$ & $94(37)$ & $18(33)$ & \\
\hline $6-10$ & $146(29)$ & $55(29)$ & $68(26)$ & $23(43)$ & \\
\hline$>10$ & $189(38)$ & $81(43)$ & $96(37)$ & $13(24)$ & \\
\hline HAQ score & $0.40 \pm 0.81$ & $0.38 \pm 0.77$ & $0.39 \pm 0.79$ & $0.53 \pm 1.01$ & 0.031 \\
\hline \multicolumn{6}{|l|}{ Comorbidity } \\
\hline Hypertension & $79(16)$ & $35(18)$ & $35(14)$ & $9(17)$ & 0.368 \\
\hline High cholesterol & $42(8)$ & $13(7)$ & $20(8)$ & $9(17)$ & 0.064 \\
\hline Diabetes & $26(5)$ & $8(4)$ & $14(5)$ & $4(7)$ & 0.63 \\
\hline Migraines & $11(2)$ & $2(1)$ & $3(1)$ & $6(11)$ & $<0.001$ \\
\hline Heart condition & $8(2)$ & $0(0)$ & $8(3)$ & $0(0)$ & 0.021 \\
\hline Anxiety & $8(2)$ & $2(1)$ & $5(2)$ & $1(2)$ & 0.752 \\
\hline Depression condition & & & & & $<0.001$ \\
\hline None & $324(65)$ & $150(79)$ & $149(58)$ & $25(46)$ & \\
\hline Mild & $118(24)$ & $29(15)$ & $76(30)$ & $13(24)$ & \\
\hline Moderate to severe & $58(11)$ & $10(5)$ & $32(12)$ & $16(30)$ & \\
\hline \multicolumn{6}{|l|}{ Current medication } \\
\hline Pain (NSAIDs, oral medications) & $80(16)$ & $30(16)$ & $41(16)$ & $9(17)$ & 0.99 \\
\hline Steroids & $110(22)$ & $50(26)$ & $47(18)$ & $13(24)$ & 0.112 \\
\hline RA-related treatment & & & & & 0.004 \\
\hline DMARDs & $329(66)$ & $109(58)$ & $176(68)$ & $44(81)$ & \\
\hline DMARDs + biologic agent & $113(23)$ & $48(25)$ & $59(23)$ & $6(11)$ & \\
\hline Biologic agent & $58(12)$ & $32(17)$ & $22(9)$ & $4(7)$ & \\
\hline Matching quality & & & & & $<0.001$ \\
\hline Bad or poor fit & $189(38)$ & $46(24)$ & $103(40)$ & $40(74)$ & \\
\hline Good fit & $311(62)$ & $143(76)$ & $154(60)$ & $14(26)$ & \\
\hline
\end{tabular}

Values in table are presented as the mean \pm SD or as the number if respondents with the percentage of total in each column in parenthesis

$P$ values are based on the chi-square test

$D M A R D s$ Disease-modifying antirheumatic drug, HAQ Stanford Health Assessment Questionnaire, NSAIDs nonsteroidal anti-inflammatory drugs, $R A$ rheumatoid arthritis 
Table 4 Patient satisfaction by degree of depression

\begin{tabular}{|c|c|c|c|c|c|}
\hline Characteristics & $\begin{array}{l}\text { Overall patient } \\
\text { sample }\end{array}$ & $\begin{array}{l}\text { Patients with no } \\
\text { depression }\end{array}$ & $\begin{array}{l}\text { Patients with mild } \\
\text { depression }\end{array}$ & $\begin{array}{l}\text { Patients with severe } \\
\text { depression }\end{array}$ & $P$ value \\
\hline Patients & 500 & $324(65)$ & $118(24)$ & $58(11)$ & \\
\hline $\begin{array}{l}\text { Preference to be } \\
\text { involved (SDM) }\end{array}$ & & & & & 0.13 \\
\hline Important & $259(52)$ & $182(56)$ & $52(44)$ & $25(43)$ & \\
\hline Somewhat important & $206(41)$ & $122(38)$ & $56(47)$ & $28(48)$ & \\
\hline Unimportant & $33(7)$ & $20(6)$ & $10(9)$ & $5(9)$ & \\
\hline $\begin{array}{l}\text { Current consideration } \\
\text { by physicians }\end{array}$ & & & & & $<0.001$ \\
\hline High & $231(46)$ & $171(53)$ & $45(38)$ & $15(26)$ & \\
\hline Somewhat & $240(48)$ & $139(43)$ & $69(58)$ & $32(55)$ & \\
\hline Not much & $29(6)$ & $14(4)$ & $4(3)$ & $9(16)$ & \\
\hline Matching quality & & & & & 0.013 \\
\hline Bad or poor fit & $189(38)$ & $113(35)$ & $44(37)$ & $32(55)$ & \\
\hline Good fit & $311(62)$ & $211(65)$ & $74(63)$ & $26(45)$ & \\
\hline Treatment satisfaction & & & & & $<0.001$ \\
\hline Not satisfied & $54(11)$ & $25(8)$ & $13(11)$ & $16(28)$ & \\
\hline Somewhat satisfied & $257(51)$ & $149(46)$ & $76(64)$ & $32(55)$ & \\
\hline Very satisfied & $189(38)$ & $150(46)$ & $29(25)$ & $10(17)$ & \\
\hline
\end{tabular}

Values in table are presented as the number if respondents with the percentage of total in each column in parenthesis $P$ values are based on chi-square test

SDM Shared decision-making

The results of the treatment preference fit index, grouped by level of depression, are shown in Table 4 . For the entire sample, the large majority of patients (93\%) valued SDM as "important" and "somewhat important, 94\% were highly or somewhat involved in the SDM, and $89 \%$ were very or somewhat satisfied. However, only $62 \%$ were in a situation of a "good" fit. For depressed patients, the fit was much lower: while 53 of 58 (91\%) patients with severe depression considered being involved in SDM either "very" or "somewhat important," nine of $58(16 \%)$ reported not to be involved, and 32 (55\%) scored "poor" or "bad" on the fit measure. Among patients with no signs of depression, $150(46 \%)$ reported to be satisfied with their treatment. In contrast, among patients with severe depression, 48 (83\%) were "not" or only "somewhat" satisfied, and among patients with mild depression, 89 (76\%) were "not" or only "somewhat" satisfied.

\section{Determinants of Patient Satisfaction}

The results of ordered logistic regression analysis, with the three levels of satisfaction as the categorical dependent variables, are reported in Table 5. These results are reported as odds ratios (OR), with an OR of $>1$ indicating that respondents with that specific characteristic had a higher degree of satisfaction compared to the reference group. Model 1 is the full model; Model 2 includes the interaction term between 
Table 5 Results of the ordered logistic regression analysis with the three levels of satisfaction as the categorical dependent variables

\begin{tabular}{|c|c|c|}
\hline Characteristics & Model $1^{a}$ & Model $2^{a}$ \\
\hline Age & $0.99(0.96-1.02)$ & $0.99(0.97-1.01)$ \\
\hline \multicolumn{3}{|l|}{ Gender (reference: male) } \\
\hline Female & $1.08(0.62-1.86)$ & $1.04(0.61-1.80)$ \\
\hline \multicolumn{3}{|c|}{ Marriage status (reference: single) } \\
\hline Married & $0.85(0.50-1.46)$ & $0.80(0.47-1.37)$ \\
\hline \multicolumn{3}{|c|}{ Highest education (reference: high school or less) } \\
\hline College & $1.49(0.84-2.66)$ & $1.50(0.84-2.66)$ \\
\hline Bachelor degree or higher & $1.17(0.76-1.78)$ & $1.17(0.76-1.79)$ \\
\hline \multicolumn{3}{|c|}{ Occupation (reference: full-time) } \\
\hline Part-time & $1.08(0.54-2.14)$ & $1.06(0.54-2.10)$ \\
\hline Housewife & $1.40(0.66-2.99)$ & $1.48(0.70-3.13)$ \\
\hline Retired & $1.64(0.56-4.77)$ & $1.81(0.62-5.28)$ \\
\hline Unemployed & $1.25(0.57-2.73)$ & $1.30(0.59-2.84)$ \\
\hline Others & $2.63(0.47-14.81)$ & $2.58(0.46-14.60)$ \\
\hline \multicolumn{3}{|l|}{ Region (reference: Hokkaido) } \\
\hline Tohoku & $1.47(0.44-4.86)$ & $1.59(0.48-5.20)$ \\
\hline Kanto & $2.11(0.87-5.10)$ & $2.30(0.95-5.50)$ \\
\hline Chubu & $2.74(1.03-7.32)$ & $2.93(1.10-7.75)$ \\
\hline Kansai & $1.92(0.74-4.96)$ & $2.00(0.78-5.13)$ \\
\hline Chugoku & $3.16(0.92-10.84)$ & $3.27(0.96-11.17)$ \\
\hline Shikoku & $2.00(0.47-8.55)$ & $1.92(0.45-8.21)$ \\
\hline Kyushu & $2.72(0.88-8.45)$ & $2.92(0.95-9.02)$ \\
\hline \multicolumn{3}{|c|}{ Annual individual income (Yen; reference $<800,000$ Yen) } \\
\hline $0.8-1.6$ million & $1.12(0.59-2.14)$ & $1.17(0.62-2.24)$ \\
\hline 1.6-3.1 million & $1.14(0.55-2.39)$ & $1.13(0.54-2.36)$ \\
\hline 3.1-3.7 million & $1.47(0.54-4.01)$ & $1.50(0.55-4.06)$ \\
\hline 3.7-5.7 million & $1.10(0.42-2.86)$ & $1.15(0.44-2.99)$ \\
\hline 5.7-7.7 million & $0.80(0.29-2.20)$ & $0.80(0.29-2.21)$ \\
\hline 7.7-9.7 million & $0.82(0.23-2.97)$ & $0.96(0.27-3.39)$ \\
\hline $9.7-11.6$ million & $2.48(0.48-12.84)$ & $2.56(0.48-13.56)$ \\
\hline 11.6-15.1 million & $2.36(0.38-14.42)$ & $2.56(0.42-15.74)$ \\
\hline$>15.1$ million & $3.81(0.21-68.57)$ & $3.44(0.19-60.36)$ \\
\hline
\end{tabular}


Table 5 continued

\begin{tabular}{|c|c|c|}
\hline Characteristics & Model $1^{\text {a }}$ & Model $2^{\mathrm{a}}$ \\
\hline \multicolumn{3}{|c|}{ Time (years) since diagnosis (reference $\leq 5$ years) } \\
\hline $6-10$ & $1.02(0.61-1.71)$ & $0.98(0.59-1.64)$ \\
\hline$\geq 10$ & $1.35(0.85-2.12)$ & $1.31(0.83-2.06)$ \\
\hline HAQ score & $0.96(0.73-1.25)$ & $0.98(0.74-1.29)$ \\
\hline \multicolumn{3}{|l|}{ Comorbidity } \\
\hline Hypertension & $1.48(0.85-2.59)$ & $1.48(0.85-2.59)$ \\
\hline High cholesterol & $0.66(0.33-1.35)$ & $0.66(0.33-1.34)$ \\
\hline Diabetes & $0.64(0.28-1.51)$ & $0.61(0.26-1.44)$ \\
\hline Migraines & $0.19(0.04-0.78)$ & $0.21(0.06-0.84)$ \\
\hline Heart condition & $0.43(0.10-1.80)$ & $0.45(0.11-1.87)$ \\
\hline Anxiety & $0.61(0.13-2.96)$ & $1.18(0.28-4.84)$ \\
\hline \multicolumn{3}{|l|}{ Current medication } \\
\hline Pain killer (NSAIDs/oral pain medication) & $0.86(0.50-1.47)$ & $0.84(0.49-1.44)$ \\
\hline Steroid & $1.53(0.95-2.48)$ & $1.54(0.95-2.48)$ \\
\hline \multicolumn{3}{|l|}{ RA-related medications (reference: DMARDs) } \\
\hline DMARDs + biologic agent & $1.58(0.98-2.56)$ & $1.58(0.98-2.56)$ \\
\hline Biologic agent & $2.22(1.19-4.15)$ & $2.22(1.18-4.15)$ \\
\hline \multicolumn{3}{|l|}{ Depression condition (reference: none) } \\
\hline Mild depression & $0.44(0.28-0.71)$ & $0.69(0.25-1.94)$ \\
\hline Moderate to severe depression & $0.22(0.11-0.43)$ & $0.55(0.09-3.27)$ \\
\hline \multicolumn{3}{|l|}{ Matching quality (reference: bad or poor fit) } \\
\hline Good fit & $2.94(1.97-4.41)$ & $4.13(1.64-10.41)$ \\
\hline \multicolumn{3}{|l|}{ Interaction term } \\
\hline Depression $\times$ matching quality & & $0.77(0.44-1.35)$ \\
\hline Pseudo- $R^{2}$ & 0.1255 & 0.1293 \\
\hline Log-likelidood & -415.45289 & -413.64442 \\
\hline
\end{tabular}

Characteristics in bold are significant at $P<0.05$ regarding an effect on level of satisfaction

Values in table are presented as the odds ratio (OR) with the confidence interval (CI) given in parenthesis Confidence intervals are based on Wald statistics

${ }^{a}$ Model 1 is the full model; Model 2 includes the interaction term between depression and treatment preference fit

depression and treatment preference fit. The results in Model 2 do not change, and the interaction term itself is also insignificant.
Regional differences were found in the level of satisfaction, with respondents from Central Japan (Chubu region) reporting a higher treatment satisfaction than those from other regions 
and respondents from Hokkaido reporting the lowest level of satisfaction. Patient satisfaction was found to be higher for high-income individuals who earn more than 9.7 million Yen per year than for those who earn less, although the effect was not statistically significant.

Patients suffering from migraines or depression exhibited significantly lower satisfaction levels. The OR for mild depression, compared to no depression, is 0.44 (95\% confidence interval [CI] 0.28-0.71), indicating a decline in the odds of satisfaction of $>50 \%$. These results are even more pronounced in Model 2. For patients with moderate to severe depression, in Model 1 the OR is 0.22 , indicating a decline in the odds of satisfaction by almost $80 \%$ (CI $0.11-0.43$ ). In contrast, overall health assessment and patient agility, as indicated in the HAQ score, were found to have no significant impact on treatment satisfaction.

Treatment with a biologic agent had a significant positive impact on patient satisfaction. While not significant, pain reduction alone may not result in the same satisfaction as steroid treatment. The biggest effect was observed in the treatment preference fit, with a coefficient of 3-4, depending on the model used, indicating that a well-matched patient is three- to fourfold more likely to be satisfied. This result is significant at the 5\% level and suggests that SDM matching benefits patient satisfaction.

\section{DISCUSSION}

There is growing evidence that depression is a common comorbidity among RA patients [41-46] and that it is associated with a significant burden of illness $[47,48]$. While prevalence of depression varies across studies, it has been estimated to be as high as $42 \%$ among RA patients [49]. In our sample, $35 \%$ of patients were identified as suffering from either mild (24\%) or severe (11\%) depression. It has also been shown that depression in Japan often remains undiagnosed [50,51]. We found that while $89 \%$ of the patients in our Japanese sample of RA patients reported being satisfied with their current treatment, only $72 \%$ of those patients with severe depression were satisfied. This difference suggests that addressing this comorbidity explicitly might enhance treatment satisfaction and thereby clinical outcomes.

Treatment preference fit was found to be an important component of satisfaction for all patients responding to the survey questions. This finding confirms the expectation confirmation theory, which was initially developed in consumer psychology [52] to model consumer satisfaction as a function of expectations, perceived performance, and disconfirmation of beliefs. This model was adapted to the healthcare setting by Alden et al. [53] to demonstrate that patient satisfaction is driven by the extent to which clinic performance meets or exceeds prior expectations. The strong impact of our preference fit index on patient satisfaction nicely shows the generalizability of consumer behavior theory even for a country with a different cultural context.

It is difficult to disentangle the effect of depression on patient satisfaction in this crosssectional setting because a low treatment satisfaction could be either the cause or the effect of a depression. Although dissatisfaction with the treatment or the physician may be an expression of depression per se, patients suffering from depression also scored lower on our preference fit index. This lower score may reflect the challenges of interaction with depressed patients, and in general indicates that doctors find it more difficult to tune into the SDM and treatment preferences of depressed patients. The interaction term between depression and treatment preference fit was not statistically significant and did not affect the independent results of each variable.

We replicate earlier results showing that biologic medication and treatment satisfaction are interlinked [54-56]. As biologics improve symptoms, this alone may increase treatment satisfaction. However, there may also be an indirect link to depression. It has been shown that patients suffering from severe depression have increased serum and/or plasma concentrations of IL-6 [57] and pro-inflammatory TNF$\alpha$ [58-60]. Also, in bipolar depression, the levels of TNF- $\alpha$ are considered to be potential markers of the disorder [21]. Medications that lower IL-6 and TNF- $\alpha$ levels may have a positive impact on 
depression [61, 62], which in turn would also improve treatment satisfaction.

We found that there was a significant regional effect, with RA patients from Japan's Chubu (central) region reporting being more satisfied with their current treatment than those from other regions in Japan. Previous studies have shown that suicide rates are lower in the Chubu region, which may be associated with a higher number of days of sunshine [63]. We leave the exploration of the geographical association with patient satisfaction for future research. In our survey, satisfaction was determined also to be numerically associated with income, which is in line with previous research on patient satisfaction $[64,65]$.

The clinical relevance of our study is that SDM per se is not the goal-perhaps in contrast to current thinking. Not all patients want to partake in treatment decisions, and some are more comfortable with the traditional role of the doctor as an authority figure who prescribes treatment unilaterally. Flexibility to adjust to the patient is key. Doctors who can determine their patients' needs and increase the SDM preference match may achieve higher patient satisfaction levels than those who always practice SDM.

\section{Limitations}

The results of this survey are a snapshot of the relation between depression and patient satisfaction in Japan. Given that depression is only just beginning to be recognized systemically in Japan, our results have some limitations. Specifically, our design does not allow for a control of acquiescence bias. As we have developed a new framework that does not utilize validated questionnaires, caution is necessary when interpreting the results, especially when it comes to causal associations. We also leave it for future research to validate the preference fit instrument on a larger scale.

\section{CONCLUSION}

Shared decision-making has been shown to benefit treatment outcomes by increasing adherence to the treatment regimen. It also reduces "doctor hopping," which is a growing phenomenon among chronic care patients, also in countries with good general healthcare programs [66, 67]. At the same time, specialty physicians often misread the SDM preferences of patients who suffer from depression. We have found strong evidence that the fit in SDM preferences is lower for depressed patients. The patient's mental health is a critical component of SDM. Especially in countries where depression remains undertreated, RA specialty physicians may improve treatment outcomes by taking mental health into account in the treatment regimen. Improving SDM preference matching and including a drug regimen that addresses both RA and depression may also bring benefits through higher patient satisfaction.

\section{ACKNOWLEDGEMENTS}

We thank the participants of the study.

Funding. This research was supported by Janssen Pharmaceutical KK, Tokyo, Japan, which also covered the publication charges. All authors had full access to all of the data in this study and take complete responsibility for the integrity of the data and accuracy of the data analysis.

Authorship. All named authors meet the International Committee of Medical Journal Editors (ICMJE) criteria for authorship for this article, take responsibility for the integrity of the work as a whole, and have given their approval for this version to be published.

Disclosures. Jörg Mahlich reports employment with Janssen Pharmaceutical KK during the conduct of the study. Ulrike Schaede reports personal fees from Janssen Pharmaceutical KK during the conduct of the study. Rosarin Sruamsiri reports employment with Janssen Pharmaceutical KK during the conduct of the study.

Compliance with Ethics Guidelines. This study was performed in accordance with the 
guidelines of all involved institutions and approved by the Janssen KK approval committee (ID 50487). This study was performed in accordance with the Helsinki Declaration of 1964 and its later amendments. Informed consent was obtained from all patients in order to collect their personal information, with the exception of individual-specific information capable of identifying individuals, which was not collected. The authors were not involved in the collection of this data. Data were collected by the database provider and patients were informed that their data would be used for research.

Data Availability. The datasets generated during and/or analyzed during the current study are available from the corresponding author on reasonable request.

Open Access. This article is distributed under the terms of the Creative Commons Attribution-NonCommercial 4.0 International License (http://creativecommons.org/licenses/ by-nc/4.0/), which permits any noncommercial use, distribution, and reproduction in any medium, provided you give appropriate credit to the original author(s) and the source, provide a link to the Creative Commons license, and indicate if changes were made.

\section{REFERENCES}

1. Charles C, Gafni A, Whelan T. Shared decisionmaking in the medical encounter: what does it mean? (or it takes at least two to tango). Soc Sci Med. 1997;44:681-92.

2. Barry MJ, Edgman-Levitan S. Shared decision making - the pinnacle of patient-centered care. N Engl J Med. 2012;366:780-1.

3. Dy SM, Purnell TS. Key concepts relevant to quality of complex and shared decision-making in health care: a literature review. Soc Sci Med. 2012;74:582-7.

4. Siegel CA, Lofland JH, Naim A, et al. Novel statistical approach to determine inflammatory bowel disease: patients' perspectives on shared decision making. Patient. 2016;9(1):79-89.
5. Lindhiem O, Bennett $\mathrm{C}$, Trentacosta $\mathrm{C}$, et al. Client preferences affect treatment satisfaction, completion, and clinical outcome: a meta-analysis. Clin Psychol Rev. 2014;34(6):506-17.

6. Kaplan SH, Greenfield S, Ware JE. Assessing the effects of physician-patient interactions on the outcomes of chronic disease. Med Care. 1989(27):S110-27.

7. Dubina M, O'Neill JL, Feldman SR. Effect of patient satisfaction on outcomes of care. Expert Rev Pharmacoecon Outcomes Res. 2009;9(5):393-5.

8. Astuti H, Nagase K. Patient loyalty to healthcare organizations: relationship marketing and satisfaction. Int J Manag Mark Res. 2014;7(2):39-56.

9. Bruera E, Sweeney C, Calder K, et al. Patient preferences versus physician perceptions of treatment decisions in cancer care. J Clin Oncol. 2001;19:2883-5.

10. Charles C, Gafni A, Whelan T, et al. Cultural influences on the physician-patient encounter: the case of shared treatment decision-making. Patient Educ Couns. 2006;63:262-7.

11. Alden DL, Friend J, Schapira M, et al. Cultural targeting and tailoring of shared decision-making technology: a theoretical framework for improving the effectiveness of patient decision aids in culturally diverse groups. Soc Sci Med. 2014;105:1-8.

12. Alden DL, Merz MY, Akashi J. Young adult preferences for physician decision-making style in Japan and the United States. Asia Pac J Public Health. 2012;24:173-84.

13. Schaede U, Mahlich J, Yoshizawa K, et al. Shared decision-making in prostate cancer treatment in japan: patient preferences versus physician perceptions. J Glob Oncol. 2018;4:1-9.

14. Bradley C, de Pablos-Velasco P, Parhofer KG, et al. PANORAMA - a European study to evaluate quality of life and treatment satisfaction in patients with type-2 diabetes mellitus e study design. Prim Care Diabetes. 2011;5:231e9.

15. Guldvog B. Can patient satisfaction improve health among patients with angina pectoris? Int J Qual Health Care. 1999;11(3):233-40.

16. Kepicoglu H, Hatipoglu E, Bulut I, et al. Impact of treatment satisfaction on quality of life of patients with acromegaly. Pituitary. 2014;17(6):557-63.

17. Young H, Bell R, Epstein R, et al. Physicians' shared decision-making behaviors in depression care. Arch Intern Med. 2008;168:1404-8. 
18. Joosten EAG, DeFuentes-Merillas L, de Weert GH, et al. Systematic review of the effects of shared decision-making on patient satisfaction, treatment adherence and health status. Psychother Psychosom. 2008;77:219-26.

19. Swanson KA, Bastani R, Rubenstein LV, et al. Effect of mental health care and shared decision making on patient satisfaction in a community sample of patients with depression. Med Care Res Rev. 2007;64:416-30.

20. Matcham F, Rayner L, Steer S, et al. The prevalence of depression in rheumatoid arthritis: a systematic review and meta-analysis. Rheumatology. 2013; 52(12):2136-48.

21. Soczynska JK, Kennedy SH, Goldstein BI, et al. The effect of tumor necrosis factor antagonists on mood and mental health associated quality of life: novel hypothesis-driven treatments for bipolar depression? Neurotoxicology. 2009;30:497-521.

22. Kaster MP, Gadotti VM, Calixto JB, et al. Depressive-like behavior induced by tumor necrosis factor$\alpha$ in mice. Neuropharmacol. 2012;62:419-26.

23. Webb KB, Golding J, Burnam DA. Psychiatric disorder in a sample of the general population with and without chronic medical conditions. Am J Psychiatry. 1988;145(8):976-81.

24. Nicassio PM. The problem of detecting and managing depression in the rheumatology clinic. Arthritis Care Res. 2008;59(2):155-8.

25. Fuller-Thomson E, Shaked Y. Factors associated with depression and suicidal ideation among individuals with arthritis or rheumatism: findings from a representative community survey. Arthritis Care Res. 2009;61(7):944-50.

26. Ishiwata R, Sakai A. The physician-patient relationship and medical ethics in Japan. Camb Q Healthc Ethics. 1994;3(1):60-6.

27. Ishikawa H, Yamazaki Y. How applicable are western models of patient-physician relationship in Asia? Changing patient-physician relationship in contemporary Japan. Int J Jpn Sociol. 2005;14: 84-93.

28. Ishikawa $\mathrm{H}$, Eto $\mathrm{M}$, Kitamura $\mathrm{K}$, et al. Resident physicians' attitudes and confidence in communicating with patients: a pilot study at a Japanese university hospital. Patient Educ Couns. 2014;96: 361-6.

29. Teo A. The current state of medical education in Japan: a system under reform. Med Educ. 2007;41:302-8.
30. Morishige R, Nakajima H, Yoshizawa K, et al. Preferences regarding shared decision-making in japanese inflammatory bowel disease patients. Adv Ther. 2017;33(12):2242-56.

31. Sekimoto M, Asai A, Ohnishi M, et al. Patients' preferences for involvement in treatment decision making in Japan. BMC Fam Pract. 2004;5(1):1.

32. Nakagawa A, Grunebaum M, Ellis S, et al. Association of suicide and antidepressant prescription rates in Japan, 1999-2003. J Clin Psychiatry. 2007;68(6):908-16.

33. Kantor E, Rehm C, Haas J, et al. Trends in prescription drug use among adults in the United States from 1999-2012. JAMA. 2015;314(17): 1818-31.

34. Margaretten M, Yelin E, Imboden J, et al. Predictors of depression in a multiethnic cohort of patients with rheumatoid arthritis. Arthritis Rheum. 2009;61(11):1586-91.

35. Sheehy C. Depression in rheumatoid arthritis-underscoring the problem. Rheumatology. 2006; 45(11):1325-7.

36. Mahlich J, Matsuoka S, Sruamsiri R. Shared decision making and treatment satisfaction in Japanese patients with inflammatory bowel disease. Dig Dis. 2017;35(5):454-62.

37. Matsuda Y, Singh G, Yamanaka H, et al. Validation of a Japanese version of the Stanford Health Assessment Questionnaire in 3,763 patients with rheumatoid arthritis. Arthritis Rheum. 2003;49(6): 784-8.

38. Suzuki K, Kumei S, Ohhira M, et al. Screening for major depressive disorder with the Patient Health Questionnaire (PHQ-9 and PHQ-2) in an outpatient clinic staffed by primary care physicians in Japan: a case control study. PLoS One. 2015;10(3):e0119147.

39. Baars JE, Markus T, Kuipers EJ, et al. Patients' preferences regarding shared decision-making in the treatment of inflammatory bowel disease: results from a patient-empowerment study. Digestion. 2010;81(2):113-9.

40. Vogel BA, Helmes AW, Hasenburg A. Concordance between patients' desired and actual decisionmaking roles in breast cancer care. Psycho-Oncology. 2008;17(2):182-9.

41. Abdel-Nasser AM, Abd El-Azim S, Taal E, et al. Depression and depressive symptoms in rheumatoid arthritis patients: an analysis of their occurrence and determinants. Br J Rheumatol. 1998; 37(4):391-7. 
42. Wright GE, Parker JC, Smarr KL, et al. Age, depressive symptoms, and rheumatoid arthritis. Arthritis Rheum. 1998;41(2):298-305.

43. Pincus T, Griffith J, Pearce S, et al. Prevalence of selfreported depression in patients with rheumatoid arthritis. Br J Rheumatol. 1996;35(9):879-83.

44. Dickens C, McGowan L, Clark-Carter D, et al. Depression in rheumatoid arthritis: a systematic review of the literature with meta-analysis. Psychosom Med. 2002;64(1):52-60.

45. Lowe B, Willand L, Eich W, et al. Psychiatric comorbidity and work disability in patients with inflammatory rheumatic diseases. Psychosom Med. 2004;66(3):395-402.

46. Isik A, Koca SS, Ozturk A, et al. Anxiety and depression in patients with rheumatoid arthritis. Clin Rheumatol. 2007;26(6):872-8.

47. Guelfucci F, Kaneko Y, Mahlich J, et al. Cost of depression in Japanese patients with rheumatoid arthritis: evidence from administrative data. Rheumatol Ther. 2018;5(1):171-83.

48. Sruamsiri R, Mahlich J, Tanaka E, et al. Productivity loss of Japanese patients with rheumatoid arthritis-a cross-sectional survey. Mod Rheumatol. 2018;28(3):482-9.

49. Bruce TO. Comorbid depression in rheumatoid arthritis: pathophysiology and clinical implications. Curr Psychiatry Rep. 2008;10(3):258-64.

50. Sruamsiri R, Kaneko Y, Mahlich J. The underrated prevalence of depression in patients with rheumatoid arthritis: evidence from a nationwide survey in Japan. BMC Rheumatol. 2017;1:5.

51. Kitanaka J. Depression in Japan: psychiatric cures for a society in distress. Princeton: Princeton University Press; 2012.

52. Oliver R. Effect of expectation and disconfirmation on postexposure product evaluations-an alternative interpretation. J Appl Psychol. 1977;62(4): 480-6.

53. Alden D, Do M, Bhawuk D. Client satisfaction with reproductive health-care quality: integrating business approaches to modeling and measurement. Soc Sci Med. 2004;59(11):2219-32.

54. Barton JL. Patient preferences and satisfaction in the treatment of rheumatoid arthritis with biologic therapy. Patient Preference Adherence. 2009;3:335-44.

55. Fraenkel L, Bogardus ST, Concato J, et al. Patient preferences for treatment of rheumatoid arthritis. Ann Rheum Dis. 2004;63(11):1372-8.
56. Goekoop-Ruiterman YP, de Vries-Bouwstra JK, Allaart CF, et al. Patient preferences for treatment: report from a randomised comparison of treatment strategies in early rheumatoid arthritis (BeSt trial). Ann Rheum Dis. 2007;66(9):1227-32.

57. Alesci S, Martinez PE, Kelkar S, et al. Major depression is associated with significant diurnal elevations in plasma interleukin-6 levels, a shift of its circadian rhythm, and loss of physiological complexity in its secretion: clinical implications. J Clin Endocrinol Metab. 2005;90(5):2522-30.

58. Tuglu C, Kara SH, Caliyurt O, et al. Increased serum tumor necrosis factor-alpha levels and treatment response in major depressive disorder. Psychopharmacology. 2003;170(4):429-33.

59. Hestad KA, Tonseth S, Stoen CD, et al. Raised plasma levels of tumor necrosis factor alpha in patients with depression: normalization during electroconvulsive therapy. J ECT. 2003;19(4):183-8.

60. Kahl KG, Greggersen W, Rudolf S, et al. Bone mineral density, bone turnover, and osteoprotegerin in depressed women with and without borderline personality disorder. Psychosom Med. 2006;68: 669-74.

61. Krügel U, Fischer J, Radicke $S$, et al. Antidepressant effects of TNF- $\alpha$ blockade in an animal model of depression. J Psychiatr Res. 2013;47:611-6.

62. Valkanova V, Ebmeier KP, Allan CL. CRP, IL-6 and depression: a systematic review and meta-analysis of longitudinal studies. J Affect Disord. 2013; 150(3):736-44.

63. Schaede U. Sunshine and suicides in Japan: revisiting the relevance of economic determinants of suicide. Contemp Jpn. 2013;25(2):105-26.

64. Chen Q, Beal E, Okunrintemi V, et al. The association between patient satisfaction and patient-reported health outcomes. J Patient Exp. 2018. https://doi.org/10.1177/2374373518795414.

65. Okunrintemi V, Khera R, Spatz E, et al. Association of income disparities with patient-reported healthcare experience. J Gen Intern Med. 2019. https:// doi.org/10.1007/s11606-019-04848-4.

66. Graugaard PK, Eide H, Finset A. Interaction analysis of physician-patient communication: the influence of trait anxiety on communication and outcome. Patient Educ Couns. 2003;49(2):149-56.

67. Guo Y, Kuroki T, Yamashiro S, Koizumi S. Illness behaviour and patient satisfaction as correlates of self-referral in Japan. Fam Pract. 2002;19(4):326-32. 